\title{
Necessidades formativas para a docência: perspectivas de professores e gestores do IFRN
} Training needs for teaching: perspectives of IFRN teachers and managers

\author{
Rejane Barros Barros*, Betania Leite Ramalho**, Isabel Carvalho Viana*** \\ *IFRN, **UFRN, ***UMinho
}

\begin{abstract}
Resumo
No complexo processo de mudança e inovação que acontece em razão da reconfiguração da identidade institucional dos Instituto Federal de Educação, Ciência e Tecnologia-IFRN/Brasil, o coletivo dos professores e sua formação se instituem como uma dimensão de essencial importância para responder aos desafios que as mudanças colocam aos professores. Essa situação requer uma revisão substantiva no que se refere à formação continuada e ao seu papel nos processos de renovação e inovação das práticas docentes e curriculares. O estudo analisa a visão de professores bacharéis e gestores do IFRN sobre a dimensão profissional da docência.

Palavras-chave: Docência; Educação Profissional e Tecnológica; Necessidades Formativas.
\end{abstract}

\begin{abstract}
In the complex process of changes and innovation occurring due to the reconfiguration of the institutional identity of the Federal Institute of Education, Science and Technology-IFRN/Brazil, the collective of teachers and their education are established as a dimension of essential importance to respond to the challenges that such changes point out to teachers. Such situation requires a substantive revision regarding continuing education and its role in the renewal and innovation processes of teaching and curricular practices. This study analyzes the view of both IFRN bachelor teachers and managers on the professional dimension of teaching.

Keywords: Teaching; Professional and Technological Education; Teachers' education Needs.
\end{abstract}

\section{Introdução}

O estudo analisa a visão de professores do IFRN sobre a dimensão profissional da docência, pondo foco na formação e na atuação destes no processo de ensinoaprendizagem. A pesquisa empírica envolveu 199 professores bacharéis e 10 gestores do citado Instituto, cuja maioria acedeu à docência sem qualquer experiência em sala de aula, embora sob a chancela de concurso público. Esse fato já sinaliza para uma excepcionalidade no acesso desses professores ao magistério da educação básica, onde estão alocados sem a formação exigida pela LDB/1996: licenciatura. Essa é uma especificidade da regulação dos Institutos após as mudanças que ocorreram no seu perfil e na sua nova identidade. Dada a natureza do objetivo e do problema em questão, trata-se de um estudo de caso, tendo envolvido diferentes procedimentos e instrumentos de coleta de dados, como a análise documental, o inquérito por questionário, a entrevista semiestruturada e o grupo focal. Nesse sentido, foi indispensável dar voz aos professores e gestores que, em sua maioria, reconhecem a necessidade de formação pedagógica contínua para melhor compreender e agir profissionalmente no exercício da docência, principalmente quando se observam os atuais desafios institucionais decorrentes da expansão dos IF no RN.

Os Institutos Federais são instituições de educação superior, básica e profissional, pluricurriculares e multicampi, integrantes da Rede Federal EPT. A partir da Lei n. 11.892/2008 amplia a sua função social passando a atuar na educação básica, na educação técnica de nível médio, na educação superior em nível de graduação tecnológica e licenciatura para formação de professores, além de pós-graduação Lato Sensu e Stricto Sensu. Essa amplitude formativa requer que os professores lecionem em diferentes níveis e modalidades de ensino.

É no contexto dessa nova realidade do Instituto, desafiado a consolidar a dimensão do ensino, da pesquisa e da extensão, abrangendo áreas de formação bastante diversificadas, que o estudo se situa. Volta-se para a formação e a atuação de professores bacharéis da Educação Profissional e Tecnológica (EPT) e toma como objetivo principal analisar a visão dos professores bacharéis sobre a dimensão profissional da docência e as interfaces entre a formação profissional e a atuação docente.

Do ponto de vista metodológico, trata-se de um estudo de caso, tendo envolvido diferentes procedimentos e instrumentos de coleta de dados, como a análise documental, o inquérito por questionário, a entrevista semiestruturada e o grupo focal. O estudo procurou dar voz aos professores e gestores para identificar suas necessidades formativas para a docência. A maioria reconhece a necessidade de formação pedagógica continuada para lograr uma melhor compreensão acerca do trabalho em sala de aula. Chegam a revelar temas considerados necessidades formativas a serem potencializadas por meio dos saberes didáticos e pedagógicos dos conhecimentos, o que resultou na proposta de criação de um Programa de Formação e Atualização Pedagógica-PFAP a ser assumido, institucionalmente. 


\section{Atuação profissional de professores bacharéis no IFRN}

No contexto da Rede Federal de Educação Profissional e Tecnológica, com a expansão e interiorização dos Institutos Federais em todos os estados do Brasil, o IFRN tem realizado esforços institucionais e investimentos, visando o cumprimento da sua nova função social. Muitas ações foram desenvolvidas, a partir de então, com vistas a potencializar as mudanças em curso: inauguração de 15 novos campi, totalizando 21 campi em 2016, contratação de servidores, aquisição de equipamentos e elevação do número de matrículas. De acordo com dados apresentados no Relatório de Gestão do Exercício 2015 (IFRN, 2016, p. 83), em 2015 a instituição atingiu o número de matrículas de 32.704 estudantes em cursos originários executados com orçamento do IFRN, além de 4.678 matrículas possibilitadas por recursos descentralizados para o IFRN, totalizando 37.382 matrículas. Outras ações estratégicas foram desenvolvidas como a oferta de cursos para reitores, diretores gerais e pró-reitores, em nível nacional, por meio de parceria entre o Ministério da Educação (MEC) e a Escola Nacional de Administração Pública.

No âmbito local, o incentivo a cursos de formação continuada, de acordo com a política de capacitação de servidores da instituição, objetivou a elevação da titulação dos servidores docentes e dos técnicos administrativos em educação, especialmente, em nível de pós-graduação stricto sensu.

No entanto, com relação à formação pedagógica dos professores bacharéis, evidencia-se que apesar de prescrita nos documentos regulatórios (LDB, Lei n. 9.394/2006), pouco se avançou na oferta de cursos de formação pedagógica para docentes não licenciados, ação a ser assumida em caráter emergencial e provisório, como trata a Resolução n. 02/2015/CNE/MEC.

Os professores bacharéis são profissionais graduados ou pós-graduados em áreas específicas, cuja formação acadêmica não foi orientada para o ensino. A maioria assume a docência sem experiência em sala de aula, tornando-se professores ao ingressarem na carreira do Magistério do Ensino Básico, Técnico e Tecnológico da Rede Federal de Educação Profissional e TecnológicaETP, por concurso público.

Nesse sentido, em nível institucional, a formação pedagógica dos professores bacharéis ainda não foi implementada no IFRN, de forma organizada, sistematizada e institucionalizada. Embora o Projeto Político Pedagógico (PPP) do IFRN defina políticas de formação de servidores docentes e técnicos administrativos e embora exista como documento regulatório a Resolução n.65/2009/CONSUP/IFRN, que estabelece a formação para o docente ingressante na instituição durante o período do estágio probatório, não há uma política interna de formação pedagógica que possibilite a formação continuada, em serviço, capaz de responder às necessidades formativas específicas para o exercício da docência.

A Política de capacitação de servidores no âmbito do IFRN, atualizada pela Resolução n.067/2011/CONSUP/IFRN, define as normas de afastamento para capacitação e a política de progressão funcional, de acordo com o previsto na Lei $n$. 11.784/2008, que regulamenta o Magistério da EBTTEducação Básica Técnica e Tecnológica. No entanto, vários professores procuram qualificar-se nas áreas específicas da formação inicial, em detrimento da busca pela formação pedagógica.

De acordo com os resultados evidenciados na pesquisa, nota-se que existe uma grande preocupação com a elevação do nível de escolaridade dos professores e também dos servidores técnicos administrativos, tanto em nível macro, nas políticas públicas e programas implementados pelo Governo Federal, como em nível micro, nas políticas internas de desenvolvimento de pessoal, objetivando a elevação da titulação do servidores para dar respostas às exigências do sistema de avaliação institucional no tocante ao desempenho dos servidores em geral.

De acordo com o enquadramento teórico que sustenta o estudo, a formação de professores no Brasil ocorre, principalmente, por meio de Programas de caráter provisório e emergencial (CABRAL NETO, 2007). Observa-se a inexistência de políticas públicas de Estado voltadas para a formação dos professores, de forma efetiva e perene, especialmente, para a formação pedagógica de professores bacharéis e tecnólogos que atuam na EPT. Apesar dos diversos programas de incentivo em nível de pós-graduação, com a disponibilização de bolsas de estudos, os professores que ingressam nesses cursos geralmente optam por seguir a formação acadêmica na sua área de formação inicial e não na área de educação.

\section{Perfil e trajetória profissional dos professores bacharéis do IFRN}

Os docentes bacharéis e os demais professores do IFRN que não têm formação em licenciatura tornaram-se professores por trajetórias acadêmicas e campos de atuação profissional distintos daqueles exigidos pela legislação brasileira: Lei de Diretrizes e Bases da Educação-LDB. Usufruem de uma regulação específica para os Institutos Federais, permitindo, portanto, que tanto a contratação como o exercício da docência se dê sem a formação superior de licenciatura exigida para os demais docentes da educação básica em geral. Assim, salienta-se que a maioria dos docentes sujeitos deste estudo não tem formação acadêmica orientada para o ensino como também não vivenciaram a dinâmica própria da docência, mesmo informalmente.

$\mathrm{O}$ perfil e a trajetória profissional dos professores bacharéis evidenciam uma formação acadêmica heterogênea, configurando docentes com diferentes perfis profissionais formados em áreas específicas inerentes aos cursos ofertados pelo Instituto, seja em nível médio, superior ou pós-graduado. São docentes que têm um saber específico e necessário à instituição, cuja prática educativa incide, majoritariamente na formação técnica e tecnológica. Tornaram-se professores seguindo trajetórias formativas e profissionais distintas da docência, sem o domínio dos saberes pedagógicos, próprios da profissão docente, saberes esses considerados necessários para atender aos desafios da ação docente e 
aos desafios que a atual sociedade impõe aos professores e às instituições educacionais.

O questionário, como instrumento de coleta de dados, na versão online foi enviado por e-mail para a lista de professores do IFRN, campo empírico da pesquisa, totalizando 1.233 (hum mil, duzentos e trinta e três professores). Após um mês de aplicação, obteve-se 408 (quatrocentas e oito) respostas, das quais 199 (cento e noventa e nove) de professores bacharéis e demais professores não licenciados.

Os gráficos abaixo foram elaborados a partir de duas referências cruzadas: formação acadêmica em nível de Pós-Graduação - especialização, mestrado e doutorado -, e área de formação nesses níveis:

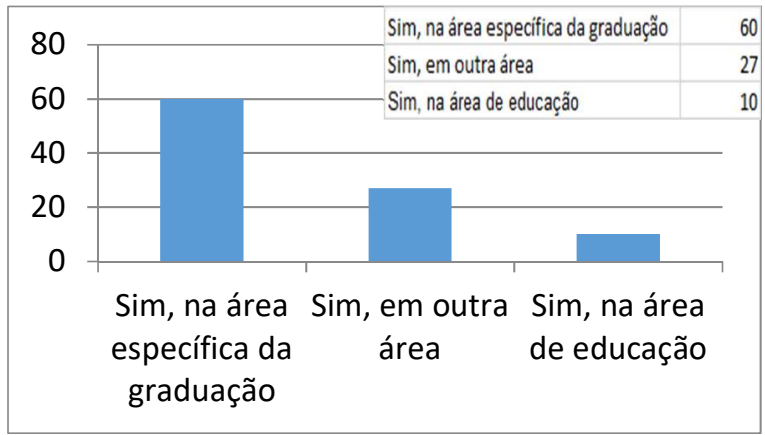

Gráfico 1. Formação dos docentes por Área em PósGraduação - Especialização

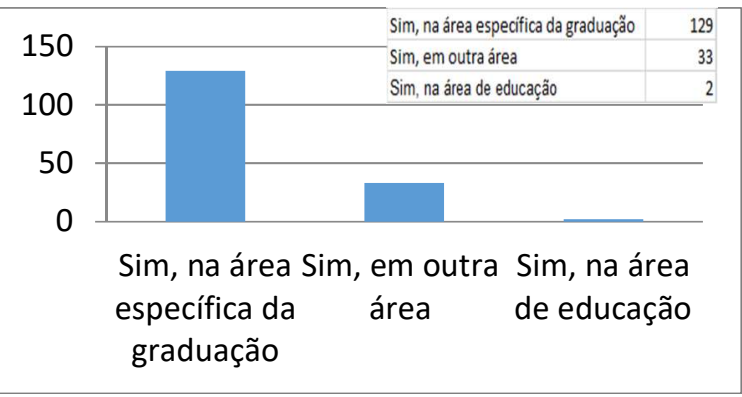

Gráfico 2. Área de formação dos docentes em Pós Graduação-Mestrado

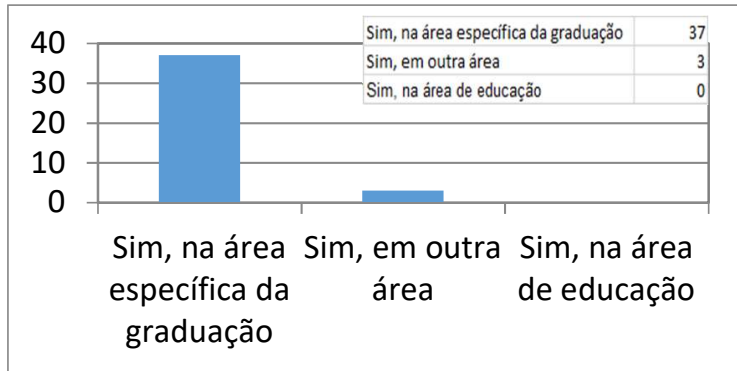

Gráfico 3. Área de formação dos docentes em PósGraduação-Doutorado

Observa-se que a maioria dos professores tem elevado nível de qualificação nas áreas específicas. Dos 199 professores que responderam ao questionário, 40 têm curso de Pós-graduação stricto sensu em nível de doutorado, mas apenas 3 cursaram na área de educação. 164 (cento e sessenta e quatro) professores têm curso de Pós-graduação lato sensu em nível de mestrado, sendo 2 na área de educação. 97 (noventa e sete) professores têm Pós-graduação lato sensu em nível de especialização, sendo 10 na área de educação. Os dados mostram que a maioria dos professores procura seguir uma carreira acadêmica nas áreas específicas, com foco na área disciplinar da formação inicial, em detrimento de formação na área de educação. Com relação às áreas de formação acadêmica predominantes em nível de graduação, entre os professores inquiridos, 34 (17\%) são da área da Ciência da Computação; 30 (15\%) são da Engenharia Elétrica; 22 (11\%) são da área de Administração, Ciências Contábeis e Turismo; 16 (8\%) são da Engenharia Civil e 8 (4\%) da Engenharia Mecânica, 7 (3,5\%) são da área de Engenharia de Produção, 7 (3,5\%) são da área de Ciências Agrárias e 75 $(38 \%)$ estão distribuídos em outras áreas da CAPES, conforme demonstrado no gráfico a seguir.

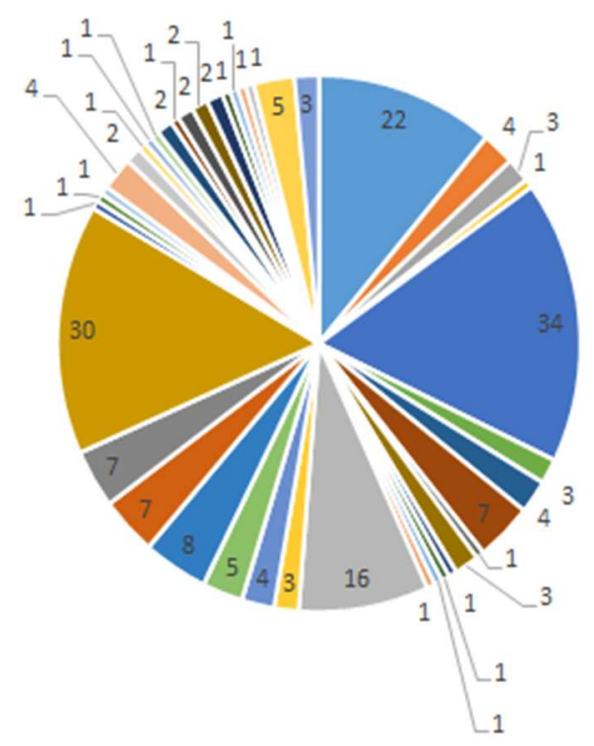

Gráfico 4. Formação Académica - Graduação/Áreas/CAPES

Portanto, em se tratando das áreas de formação inicial em nível de graduação, os docentes bacharéis e tecnólogos têm formação acadêmica bastante heterogênea em razão do leque de formações ofertadas. Existe um grande número de professores com elevado nível de formação acadêmica e qualificação profissional, conforme dados apresentados no capítulo da análise e interpretação dos resultados.

Observa-se que anteriormente ao ingresso no IFRN, a maioria dos professores trabalhava em instituições privadas, num total de 108 (cento e oito). Outros 58 (cinquenta e oito) professores, além de terem trabalhado em instituições privadas, também já atuaram em instituições públicas, municipais, estaduais ou federais. Sessenta e quatro professores já trabalharam em outra instituição da esfera federal.

Para 25 professores, o IFRN é o primeiro emprego. Outro dado importante diz respeito ao número de professores que nunca lecionaram antes do ingresso no 
IFRN: 83 professores, $42 \%$, não registraram nenhuma experiência anterior na docência.

Quanto ao tempo de ingresso, os dados mostram a extrema necessidade de a instituição investir em processos formativos dos professores, especialmente para os ingressantes, considerando que, 81 professores (41\%) ingressaram no IFRN há menos de três anos. Desses 81 professores, 33 ingressaram há menos de um ano na instituição e 48 entre um e três anos; 80 professores (40\%) ingressaram entre 4 e 10 anos, 29 $(14,5 \%)$ entre 11 e 25 anos e $9(4,5 \%)$ há mais de 26 anos. É preocupante o fato da instituição não estar ofertando cursos voltados para a formação pedagógica dos professores ingressantes, mesmo durante o período do estágio probatório, isto é, nos três primeiros anos de trabalho, conforme prescrito na Resolução n. 065/2009/CONSUP/IFRN.

\section{Perfil e trajetória profissional dos gestores}

Durante este estudo foram realizadas entrevistas semiestruturadas gravadas, de forma individual, com dez gestores do IFRN, tendo sido convidados a participar cinco homens e cinco mulheres. Entre os dez gestores entrevistados, oito têm cargo de docente, exercendo função de gestão; duas são pedagogas atuando no cargo de técnico administrativo em educação, membros da Equipe Técnico-Pedagógica.

Com relação à formação acadêmica, os dados mostram que a instituição dispõe de um quadro de gestores com elevado nível de qualificação profissional. Dos dez gestores entrevistados (as), cinco são bacharéis em Engenharia, sendo que um deles, além de engenheiro, é também matemático. Três têm licenciatura plena em Pedagogia, um tem licenciatura em Educação Física e um tem graduação em Tecnologia Mecânica.

Dos dez entrevistados, alguns têm mais de uma graduação e a maioria tem pós-graduação Stricto Sensu: quatro tem doutorado, sendo que desses apenas um tem doutorado na área de Educação. Os demais cursaram doutorado em áreas específicas da Engenharia. Cinco têm mestrado, sendo apenas um na área de Educação e os demais em áreas específicas da engenharia; um gestor tem especialização em Educação, três deles estão cursando doutorado, um tem especialização e está cursando mestrado. Cabe ressaltar que quatro, dos dez gestores entrevistados, têm formação acadêmica em nível de graduação na área de Educação e seis são professores bacharéis ou tecnólogos.

A maioria dos gestores já assumiu outros cargos de gestão na instituição e também em outras instituições antes de ingressarem no IFRN, tendo, portanto, bastante experiência como gestores, tendo o tempo de ingresso na instituição há, pelo menos, cinco anos. Metade dos gestores trabalha na instituição há mais de dezessete anos, sendo que dois deles já são servidores há 33 anos.

Ao serem questionados sobre a trajetória profissional, objetivando conhecer e estabelecer uma relação dessa trajetória com o ingresso na docência, os gestores entrevistados fizeram uma narrativa de suas histórias de vida antes e depois do ingresso no IFRN. Falaram como iniciaram a carreira profissional, destacando fatos ou pessoas que influenciaram na escolha da docência como profissão, especialmente os seis professores bacharéis que tiveram uma formação acadêmica em outra área completamente diferente da educação. Os quatro gestores que têm formação acadêmica na área de educação, após concluírem a graduação, iniciaram as suas atividades em sala de aula em escolas particulares e também em escolas da rede pública municipal e estadual.

\section{Formação contínua e desenvolvimento profissional de professores}

Neste estudo, evidencia-se que os saberes docentes dos professores bacharéis e tecnólogos advêm, principalmente, da formação inicial nas áreas técnicas e tecnológicas, sendo enriquecidos com as experiências profissionais nas quais ganham destaque o saber fazer, o saber ser e o saber pensar, habilidades inerentes ao desenvolvimento profissional (Ramalho e Nuñez, 2014). Nesse sentido, faz-se necessária a valorização desses saberes específicos e especializados para o ensino na Educação Profissional e Tecnológica, como também o investimento e esforços institucionais para proporcionar a formação pedagógica para o docente bacharel, de forma a permitir o avanço com mais força do seu desenvolvimento profissional. Machado (2008) salienta que a formação pedagógica dos professores, para atuação na EPT, é uma demanda que vem crescendo ao longo da história. Portanto, deve ser potencializada, em nível macro, permanente, para superar o caráter emergencial e efetivar-se como política da instituição.

A formação continuada, na pesrpctiva defendida por Ramalho e Nuñez (1995) é mais que instrução ou aprendizagem de conhecimentos e formação de habilidades e de competências, pois inclui, entre outras coisas, interesses, necessidades, intenções, motivações, caráter, capacidades, condutas, crenças, atitudes e valores. Esses elementos possibilitam a formação de competências e, consequentemente, um novo estágio, qualitativamente diferente, no desenvolvimento profissional. A formação é um tipo de atividade em que o professor se apropria da cultura profissional e modifica, sob influências externas pedagogicamente organizadas, elementos chaves do seu agir profissional, de forma a influenciar no desenvolvimento profissional.

Necessidades formativas para a docência na EPT: perspectivas de professores e gestores para a formação pedagógica

Estudiosos da formação docente (Nóvoa, 1992; Tardif e Raymond, 2000; Ramalho e Nuñez, 2014; Day, 2001; Flores e Viana, 2007) salientam que os saberes docentes advêm de fontes diversas, constituindo-se como saberes plurais e heterogêneos, podendo ser identificados como saberes da profissão inerentes à base de conhecimento do docente.

Corroborando com esses autores, entende-se que os saberes da docência são plurais e se constroem a partir de diversas fontes ao longo da carreira profissional e no caso dos professores bacharéis e tecnólogos, não é diferente. Há, portanto, a necessidade de promover a formação continuada orientada para o exercício da docência no contexto de trabalho. 
Ressalta-se que ao serem inquiridos, os professores e gestores afirmaram sentir falta de cursos promovidos pela instituição, voltados para a formação pedagógica no IFRN.

Parece haver uma superação do conhecido desinteresse docente pelo conhecimento pedagógico, ainda tão evidente em vários contextos da atividade docente.

Dos 199 professores participantes da pesquisa, 140 $(70,3 \%)$ disseram sentir falta dessa formação, reiterando ser necessário o desenvolvimento de ações formativas pedagógicas no âmbito da instituição.

\section{Temas para estudos e cursos de formação continuada}

Os temas para cursos de formação continuada sugeridos pelos professores, versam sobre: metodologias e estratégias de ensino, avaliação da aprendizagem, processos cognitivos de aprendizagem, desenvolvimento de projetos interdisciplinares, motivação dos alunos, relações interpessoais no processo ensino e aprendizagem, planejamento do trabalho pedaegógico, dentre outros.

É possível inferir que as necessidades formativas dos professores perpassam, principalmente, pelas questões relacionadas aos conhecimentos pedagógicos, potencializadores do processo ensino e aprendizagem, além de favorecerem as relações interpessoais entre docentes e alunos e os conhecimentos curriculares.

As necessidades estimulam e dirigem a atividade quando têm suas raízes na realidade profissional, como necessidades objetivas construídas no bojo das relações profissionais e no confronto com os objetos culturais produzidos pela profissão docente, ou seja, a base de conhecimentos, tal como enfatizam Ramalho; Núñez; e Gauthier (2004).

Quanto aos resultados dos dados obtidos na entrevista aos gestores, procurou-se estabelecer uma inter-relação entre os temas indicados pelos professores nos questionários e os indicados pelos gestores, na entrevista. É possível afirmar que a maioria dos temas apresentados são coincidentes, destacando-se os conhecimentos da Psicologia como processos cognitivos da aprendizagem; os conhecimentos da Pedagogia, com ênfase na Didática e metodologias de ensino; Fundamentos da Educação de forma ampla e, em particular, da Educação Profissional e Tecnológica.

A concepção de currículo integrado também foi um tema considerado como muito importante pelos gestores, uma vez que embasa a prática educativa da instituição, conforme defendido no seu PPP. O conhecimento disciplinar também foi apontado pelos gestores, bem como aulas práticas e experimentais; a articulação teoria e prática e o uso de tecnologias educacionais também foram citados. Um dos gestores entrevistados salientou que alguns professores têm dificuldades em articular teoria e prática, visto que saem da Universidade com a formação bastante acadêmica e ingressam na instituição como docentes, sem terem adquirido experiência profissional na área específica o que compromete o processo de aprendizagem dos estudantes.

Com relação às difuldades em sala de aula, destaca-se que a falta da formação pedagógica foi apontada por 40 (quarenta) professores e também pelos gestores participantes da pesquisa como um dos principais aspectos que interferem negativamente no processo de ensino e aprendizagem. Segundo os inquiridos, essa lacuna na formação pedagógica gera dificuldades para os alunos e também para o professor devido à falta de conhecimentos que contribuam para a melhoria da sua prática e para o seu desenvolvimento profissional enquanto docente.

\section{Consideraçoes finais}

Com os resultados do estudo é possível inferir que as necessidades formativas dos professores são amplas e dizem respeito, especialmente, ao conhecimento pedagógico, fato que surpreende. Esse resultado, diferente de estudos observados em outras Instituições de Ensino Superior, deve estar sendo influenciado pela estrutura do Instituto que sempre valorizou o trabalho do setor pedagógico, reconhecendo sua interface com os resultados do processo de ensino aprendizagem, além de subsidiar a organização dessa atividade no plano institucional. Também revelaram preocuparem-se em conhecer estratégias para motivar os estudantes, melhorar as relações interpessoais e a interação em sala de aula.

\section{Referências}

Bardin, L. (1977). Análise de conteúdo. Lisboa: Edições 70.

Barros, R. B. (2016). BARROS, R. B. Formação e docência de professores bacharéis na Educação Profissional e Tecnológica no IFRN: uma interface dialógica emancipatória. 2016. 337f. Tese (Doutorado em Educação) - UFRN;UMinho).

Brasil. (2008). Lei 11.892, de 29 de dezembro de 2008. Institui a Rede Federal de Educação Profissional, Científica e Tecnológica, cria os Institutos Federais de Educação, Ciência e Tecnologia, e dá outras providências. D.O.U. Poder executivo, Brasília, DF, Ano CXLV, n. 253, 30 dez. 2008. Seção 1. p. 1-3. Disponível em: <http://www.planalto.gov.br/ ccivil 03/ Ato2007-2010/2008/Lei/L11892.htm>.

Acesso em: 20 mai. 2015.

Cabral Neto, A.; et al (Orgs.) (2007). Pontos e contrapontos da política educacional: uma leitura contextualizada de iniciativas governamentais. Brasília: Liberlivro.

Day, C. (2001). Desenvolvimento profissional de professores: os desafios da aprendizagem permanente. Porto: Porto Editora.

Flores, M. A.; Viana, I. C. (Org.) (2007). Profissionalismo docente em transição: as identidades dos professores em tempos de mudança. Braga: CIEd, Universidade do Minho.

García, C. M. (1999). Formação de professores - Para uma mudança educativa. Porto: Porto Editora.

Machado, L. R. S. (2008). Diferenciais inovadores na formação de professores para a educação profissional. In: Revista Brasileira da Educação Profissional e Tecnológica, Brasília: MEC, SETEC, v.1, n. 1, junho, 2008. 
Nóvoa, A. (Org.) (1992). Os professores e a sua formação. Lisboa: Dom Quixote.

Ramalho, B. L; Nuñez, I. B. (2004). Formar o Professor. Profissionalizar o Ensino: perspectivas e desafíos. Editora Sulinas. Porto Alegre.

Ramalho, B. L; Nuñez, I. B. (2014). Formação, representação e saberes docentes. Elementos para se pensar a profissionalização dos professores. Campinas: Mercado das Letras.

Ramalho, B. L; Nuñez, I. B. (2011). Diagnóstico das necessidades formativas de profesores do ensino médio no contexto das reformas curriculares. Revista Educação em Questão, Natal, v. 40, n. 26, p. 69-96, jan./jun. 2011.

Tardif, M. (2002). Saberes docentes e formação profissional. Petrópolis: Vozes. 